\title{
The Relationship between Capital Structure and Financial Performance of the Company
}

\author{
V.V. Tretiakova ${ }^{1, *}$, M.S. Shalneva ${ }^{1}$, and A.S. Lvov ${ }^{1}$ \\ ${ }^{1}$ Financial University under the Government of the Russian Federation, Moscow, Russia
}

\begin{abstract}
The article examines and analyzes the relationship of key performance indicators (ROA, ROIC, change in market capitalization and price-to-book ratio) and the capital structure of the company based on the pharmaceutical industry in the UK for the 2009-2019 period. The study seeks to provide a practical evidence on the impact of external financing on company's financial performance and test applicability of the pecking order theory for the chosen companies. The research conducted uses panel data regression and Wald test to determine and analyze the effect of capital structure on the financial indicators of the company performance. The study used a sample of $185 \mathrm{UK}$ companies from the pharmaceutical industry. The result of the research showed that equity has negative effect on price-to-book ratio and ROA and positive effect on change in market capitalization, while long-term debt has a positive relationship with price- to-book ratio and change in market capitalization. In addition, short-term debt has a negative effect on change in market capitalization, ROA and ROIC. The study also provides only partly coincidence of the results with the pecking order theory.

Keywords: Capital Structure; Financial Performance; Market Capitalization; Return On Assets; Return On Invested Capital.
\end{abstract}

\section{Introduction}

Since the 20th century, ways to evaluate company's development have been actively discussed and explored. One of the generally accepted financial measures is considered to be company's financial performance, which represents a subjective measure of the firm's effectiveness in using assets of primary occupation and generating revenues. In addition, financial performance also indicates the overall financial health of a company for a certain period of time [4]. To improve the financial performance internal and external sources of financing are chosen by the company, which subsequently affect its capital structure. The capital structure decision is one of the most significant for businesses as it may help to maximize returns of the company and function successfully in the competitive environment. Starting from the 50s of the last century various theories of capital structure are being developed, which are trying to find the best option for firms financing that will help them develop actively and improve their performance [1].

*Corresponding author: trevishka@gmail.com 
Interestingly, very few research took the innovative industries of developed countries to study this relationship [8]. Thus, modern innovative companies remain unexplored for the relationship of their performance and capital structure. Hence, meticulous empirical study of this relationship can be relevant for a better understanding of the functioning of such companies in the modern world.

The aim of the article is to find out whether there is a relationship between capital structure and company performance indicators on the example of pharmaceutical companies in the UK. The aim is supported by the following objectives:

- To determine whether there is a relationship between capital structure and a firm's performance according to relevant literature;

- To discover the key financial indicators of the company performance;

- To examine the relationship between key financial indicators and capital structure;

- To identify the impact of external financing on the company financial performance;

- To test whether the financial resources allocation conforms one of the capital structure theories.

This study will attempt to close the previous researches' gaps and highlight any unexpected relations to get a better understanding of pharmaceutical companies' operational principles and ways to improve their financial performance, as well as allow investors to make more informed decisions regarding the financing of the above companies.

\section{Methodology}

The following research aims to empirically analyze the selected companies from pharmaceutical industry in the UK and test their relationship between capital structure and financial performance according to the hypotheses.

Since the external sources of financing of the capital structure is a combination of equity, long term and short term debt sources their impact on each indicator of financial performance will be considered separately. The following financial indicators of the company performance were selected: ROA, ROIC, DMC, PB ratio. The present research seeks to determine the impact of capital structure on the performance variables chosen and accept or reject the following hypotheses according to the following data sample analysis.

The present study examines the effect of capital structure on key financial indicators of the company's performance for UK companies in pharmaceutical industry. Therefore, based on the financial performance indicators chosen, the following hypotheses were formulated. Each hypothesis describes one of four financial indicators. The H1 states that external financing impacts negatively DMC as an indicator of company performance. The $\mathrm{H} 2$ claims that external financing impacts positively $\mathrm{PB}$ ratio as an indicator of company performance. The H3 verifies whether external financing impacts negatively ROA as an indicator of company performance. Finally, H4 examines whether external financing impacts positively ROIC as an indicator of company performance. Finally, based on testing the first four hypotheses, the H5 is formulated: financial resources allocation follows the pecking order theory.

The research uses secondary data only, since the necessary information about financial indicators of the company's performance as well as their capital structure cannot be obtained primary in the framework of this study.

The study collects data from different companies from the same industry over a long period of time. Since the data refer to the concept of "multidimensional data" and include measurements over a long period of time, it is decided to use panel study as a type of longitudinal design for econometric and statistical studies [2].

In order to measure the effect of independent variable on dependent one and test the hypotheses $\mathrm{H} 0$ and $\mathrm{H} 1$ panel data analysis techniques are applied. The hypothesis testing 
involves the use of several models: linear regression, pooled OLS panel regression model and Fixed and Random effects Panel regression model [11].

To test the relationship between capital structure and PB ratio, DMC, ROA and ROIC linear regression seems to be the best model to be applied. In a standard form, linear regression is represented by the formula:

$$
Y_{i}=\beta_{0}+\beta_{1} X_{1}+\ldots+\beta_{n} X_{n}+\varepsilon_{i}
$$

where: $Y_{i}$ - dependent variable;

$\beta_{0}$ - constant;

$\beta_{1}-\beta_{n}-$ regression coefficients;

$X_{1}-X_{n}$ - explanatory variable;

$\varepsilon_{i}-$ statistical error.

In order to find betas and build regression model the method of ordinary least squares (OLS) is used as one of the most powerful methods to apply for the panel regression [11].

In order to estimate the relationship between capital structure and ROA and ROIC as dependent variables, the regression functions were created:

$$
\begin{aligned}
& R O A_{i, t}=\beta_{0, i}+\beta_{1, i} * S T+\beta_{2, i} * L T+\beta_{3, i} * D S H+\varepsilon_{i, t} \\
& \operatorname{ROIC}_{i, t}=\beta_{0, i}+\beta_{1, i} * S T+\beta_{2, i} * L T+\beta_{3, i} * D S H+\varepsilon_{i, t}
\end{aligned}
$$

The independent variables are represented by short-term debt (ST), long-term debt (LT) and growth rate of outstanding shares (DSH), $\varepsilon_{i, t}$ implies statistical error.

For estimating the relationship between capital structure and PB ratio, ROE is included into regression model as a control variable in order to control risk if increasing the leverage. Therefore, the regression formula for PB ratio as a dependent variable is:

$$
P B \text { ratio }_{i, t}=\beta_{0, i}+\beta_{1, i} * S T+\beta_{2, i} * L T+\beta_{3, i} * R O E+\varepsilon_{i, t}
$$

By using the coefficient of determination or the coefficient of the R-squared, the study determines the possibility of applying a regression model. The R-squared as a selective correction between the predictor and the response can be measured according to the formula [11]:

$$
R^{2}=\frac{\text { Explained variation }}{\text { Total variation }}
$$

To avoid autocorrelation of random errors of the regression model and bias coefficient estimates, the autoregressive model is used in the current study to test PB ratio, ROA and ROIC.

To obtain the best results in using the OLS method for PB ratio, ROA and ROIC, the study uses the autoregressive model. Autoregression of the first and second orders is used, the processes of which are characterized by the formulas:

$$
\begin{aligned}
& A R(1): X_{t}=c+r X_{t-1}+\varepsilon_{t} \\
& A R(2): X_{t}=c+a_{1} X_{t-1}+a_{2} X_{t-2}+\varepsilon_{t}
\end{aligned}
$$

To test how capital structure affects the DMC, Pooled OLS and Fixed and Random effects Panel regression models need to be applied: 


$$
D M C_{i, t}=\beta_{0, i}+\beta_{1, i} * D S T+\beta_{2, i} * D L T+\beta_{3, i} * D S H+\varepsilon_{i, t}
$$

In case of influence of factors which are not considered in the model and random deviations dependent on companies these regression models help to avoid heterogeneity bias.

The confidence interval of the study is $90 \%$, therefore p-values at $10 \%$ level or lower propose a significant result.

Wald test is also used to verify that the impact of short-term debt and long-term debt is different when testing PB ratio, ROA and ROIC as dependent variables. The program EViews 11 was used for this task.

The analysis is based on pharmaceutical firms listed on the London Stock Exchange. Financial data was obtained by authors from the Bloomberg information system on the $22^{\text {nd }}$ of May 2020 for the period between 2009 and 2019 and consists of company financial data: D/E ratio, the number of outstanding stocks, stock price, market capitalization, long-term and short-term debt, $\mathrm{P} / \mathrm{B}$ ratio, ROE, ROA and ROIC. The primary sample consists of 203 companies. The data was exported to Excel. Due to lack of some company data, some companies were excluded from the sample. The final sample consists of 185 companies for 11 years (from January, 2009 to January, 2019) based on yearly observations.

In order to eliminate the omitted variable bias control variables are included into the model where it is necessary [11]. The Hausman test is also used to prevent false results where they are possible [3].

\section{Results}

In order to test the hypotheses $\mathrm{H} 1-\mathrm{H} 5$ and evaluate results of the research the econometric and statistical techniques mentioned in the previous chapter are applied. The hypotheses H1-H5 with a specification for DMC includes panel data regression with 132 cross-sections and a total number of 720 panel observations. Firstly, a Pooled OLS regression model is applied. The generalized formula of Pooled OLS regression presented in the Methodology subsection is changed according to the obtained values by EViews program:

$$
D M C_{i, t}=0.555374 * D S H-0.00082 * D S T+0.0000931 * D L T
$$

According to the results obtained, all independent variables have a significant factor at p-values of 0,0253 for short-term debt, 0 for long-term debt and 0 for growth rate of outstanding shares which is lower $10 \%$. The R-squared is 0,085411 which is rather low. That means that the amount of variance in the dependent variables that is predictable from the independent variables is low. Based on these results, it can be concluded that the observed outcomes are not replicated by the model well. However, the result may be incorrect due to heterogeneity bias [12]. In order to test pooled OLS for the heterogeneity bias, fixed effects model is estimated where the $\overline{R^{2}}$ should increase by adding dummy variables in the amount $n-1$. The formula mentioned in the Methodology chapter is written below according to the coefficients findings:

$$
D M C_{i, t}=0.634928 * D S H-0.00075 * D S T+0.000126 * D L T
$$

As seen from the table, the R-squared has increased and is now 0,282295, which is nearly $20 \%$ more than the previous result in pooled OLS regression model. In order to prove the significance of the model Redundant fixed effects test is conducted. According to the fixed effects model test, cross-sections fixed effects model is more significant than the 
pooled model as the p-value of cross-section $F$ test is 0,0613 and is less than $10 \%$. That means that the original data in the pooled OLS model includes heterogeneity bias. Therefore the fixed effects model is applied. In the fixed effects model all three independent variables impact significantly on DMC as a dependent variable.

Since it is always necessary to choose the application of a model of fixed or random effects, the random effects model is now applied. A Hausman test verifies the value difference between the estimates of two models in order to choose the correct one.

The following formula for the random effects model according to the results is:

$$
D M C_{i, t}=-0.04195+0.572947 * D S H-0.0008 * D S T+0.000101 * D L T
$$

With a probability result of 0,2656 which is more than $10 \%$ Hausman test shows that the difference between values of the estimators is not significant, therefore the null hypothesis is accepted and consequently the random effects model is appropriate for the current study.

As a result, the random effects regression model reveals that all independent variables have an impact on changes in the market capitalisation. Delta shout and delta long-term debt with a p-value both of 0 affects DMC positively, while delta short-term debt with a pvalue of 0,0252 has a negative relationship with the dependent variable.

The analysis of the relationship between capital structure and PB ratio is presented below. The total number of observations is 521 with 104 cross-sections included. To avoid the autocorrelation of random errors of the regression model and bias coefficient estimates, the autoregressive model AR(1) and AR (2) is used. By substituting values the panel data regression for $\mathrm{PB}$ takes on the form:

$$
\begin{array}{rl}
P B \text { ratio }_{i, t} & =3.050119+0.031414 * D E-0.03628 * R O E+0.345918 * \\
A R(1)+0.442254 & * A R(2)
\end{array}
$$

The results show that there is a significant positive impact of $\mathrm{D} / \mathrm{E}$ ratio ( $\mathrm{p}$-value $=0,044$ ) and significant negative impact of $\operatorname{ROE}(p$-value $=0,01)$. However, it was decided to consider debt in particular by using such independent variables as long-term debt and shortterm debt as it gives an opportunity to verify the difference between short-term and longterm debt impact. According to the results, the current formula is:

$$
\begin{gathered}
P B \text { ratio }_{i, t}=2.850597+0.0463 * L T-0.03928 * R O E+0.348387 * A R(1)+ \\
0.408909 * A R(2)
\end{gathered}
$$

The results from EViews 11 show that long-term debt with a p-value of 0,0106, which is lower than $10 \%$, has a significant positive effect on $\mathrm{PB}$ ratio. As a control variable, ROE has a negative effect on PB ratio with p-value of 0,005 as well. Short-term debt is not considered as statistically significant factor as its probability is 0,1549 , which is higher than $10 \%$ p-value taken for the study.

Since short-term and long-term debts are a part of $\mathrm{D} / \mathrm{E}$ ratio as a percentage, in order to avoid test fallacy it is necessary to test if there is a difference of impact of long-term and short-term debt. For this reason Wald test is applied in the following study. With Wald test the current study checks whether long-term debt and short-term debt are equal in value and therefore can be excluded from the model due to insignificance. The test conducted shows that the p-value of t-statistics (other statistic tests are not considered since only one linear constraint is checked) is 0,0101 which is less than $10 \%$, therefore the null hypothesis is rejected as there is a statistically significant difference. The two coefficients $\mathrm{C}(2)$ (short- 
term debt) and C(3) (long-term debt) are not simultaneously equal to zero or equal to each other, therefore the impact of short-term debt differs from the impact of the long-term debt, hence they are not removed from the model.

In order to measure the relationship between capital structure and ROA and ROIC, the analysis of two dependent variables is combined since both same techniques and statistical tests are conducted to determine the relation. To outline its relationship of ROA with shortterm debt, long-term debt and delta shout panel data regression with 103 cross-sections and 470 observations is created. The formula for the ROA panel data regression according to the results is:

$$
\begin{aligned}
& R O A_{i, t}=-35.2797-0.05902 * S T-18.3895 * D S H+0.556996 * A R(1)+ \\
& 0.323419 * A R(2)
\end{aligned}
$$

As can be seen from the table, the probability of short-term debt is 0,0017 and lower than $10 \%$ whereas long-term debt has a p-value of 0,645 , which is higher than the probability determined for the current study. Therefore, short-term debt impacts ROA negatively, while long-term debt does not have any influence on the financial performance indicator mentioned. DSH has the most significant negative impact on ROA with the coefficient of $-18,3895$ and $p$-value of 0,0043 . In order to test the difference in value of short-term and long term debt the Wald test is taken. The Wald test shows the p-value of $\mathrm{t}$ statistics is at level of 0,0025 and is less than $10 \%$, therefore the null hypothesis is rejected, where $\mathrm{C}(2)$ is short-term debt and C(3) is long-term debt, therefore the impact of short-term debt and the long-term debt is different and they do not need to be removed from the model.

The panel data analysis for ROIC as a dependent variable includes 104 cross-sections and 473 total panel observations. Since ROIC takes significantly negative values in the chosen sample of companies, it was also decided to bring the indicator to the exponential form, thus the dependent variable is $\operatorname{EXP}(\mathrm{ROIC} / 100)-1$. Wald test is also conducted to exclude the identity between values of long-term and short-term debts. According to the results the formula for the ROIC panel data regression is:

$$
R O I C_{i, t}=-0.40157-0.00054 * S T+0.601243 * A R(1)+0.31541 * A R(2)
$$

The probability of t-statistic in Wald test is less than $10 \%$, therefore there is a difference in impact between short-term debt and long-term debt, hence the panel data regression analysis is applicable for these independent variables.

Panel data regression for ROIC indicates the significant impact of short-term debt (with p-value of 0,0058$)$ only. The p-values of long-term debt $(0,5265)$ and delta shout $(0,8378)$ show absence of statistical significance of the independent variables.

\section{Discussion}

In accordance with findings, the results were combined into the Table 2 in order to give a more demonstrative view. The first column represents investigated financial indicators of the company performance, the subsequent columns point out the relationship between dependent variables and equity, long-term and short-term debts. Positive impact is indicated by "+” symbol, negative impact - by “_" symbol and absence of any relationship is represented by "N/A". 
Table 1. Analysis of results

\begin{tabular}{|c|c|c|c|}
\hline Dependent variable & Equity & Long-term debt & Short-term debt \\
\hline DMC & + & + & - \\
\hline PB ratio & - & + & N/A \\
\hline ROA & - & N/A & - \\
\hline ROIC & N/A & N/A & - \\
\hline
\end{tabular}

Source: Own processing.

Based on the table above, certain conclusions need to be drawn. Firstly, all elements of capital structure follow approximately the same trend in the impact on the key indicators of financial performance of the company. This can be seen as a positive sign that the research is done correctly.

DMC has a significant positive relationship with equity and long-term debt and negative relationship with a short-term debt. This means that equity financing and long-term debt increases the level of market capitalization. Therefore, the hypothesis $\mathbf{H 1}$ must be rejected.

The findings related to the relationship of PB ratio and capital structure components show that PB ratio corresponds positively with ROE which presents equity and negatively with short-term debt. This only partly corresponds with the hypothesis, thus it concludes that $\mathbf{H} 2$ hypothesis is rejected.

It is found that ROA has a negative relationship with equity and short-term debt. This is partly consistent with Salim and Yadav (2012) who test Malaysian firms and find the negative relationship between short-term debt and ROA [9]. However, this contradicts the argument of Mehdi \& et al., (2013) who also test pharmaceutical firms and state that there is no relationship between short-term debt and ROA and negative relationship between long-term debt and ROA, which are the opposite results to the current research [6]. The difference in results could be due to another time period and country chosen, as well as the difference in countries' economies and their level of the development. According to the findings results, the hypothesis $\mathbf{H 3}$ should be accepted.

Surprisingly, ROIC shows no relationship with equity and long-term debt and negative relationship with short-term debt. This disagrees with Nasimi (2016) paper which states that ROIC has a positive relationship with debt to equity ratio. Hence, the $\mathbf{H} 4$ hypothesis is rejected [7].

In conclusion, it should be noted that the impact of equity on financial performance indicators is worse than the impact of long-term debt. There is a negative relationship between equity and 2 out of 4 financial indicators, while long-term debt affects positively 2 out of 4 financial indicators and does not have any impact on the rest ones. This provides an evidence for the pecking order theory and acceptance of H5 [5]. However, short-term debt impacts even more negatively than equity does, which is not corresponded with the pecking order theory [10]. As a result, the findings partly follow the pecking order theory, hence the H5 hypothesis is rejected.

\section{Conclusion}

The research has shown that long-term debt has a positive impact on such dependent variables as DMC and PB ratio, short-term debt negatively affects DMC, ROA and ROIC and equity negatively impacts $\mathrm{PB}$ ratio and ROA, while DMC positively. Thus, 4 of the 5 proposed hypotheses were rejected.

The current study suggests practical implications of the research conducted for the companies and investors. As it was stated in the introduction, company's performance is one of the fundamental financial indicators to measure the company's level of development 
and it also impacts the investment decisions. In this study information was obtained on the impact of capital structure on financial performance indicators in pharmaceutical companies in developed countries using the example of the UK. This allows companies to get correct estimation of their capital structure and optimize it better in order to improve the indicators of their performance. The study also provides management with the information on how debt impacts the financial performance of the pharmaceutical company. It could be used for making strategic decisions in order to achieve maximized profits, and lead to the rise of market capitalization. It is also important for making competent decisions regarding the activities of the company and raising funds in such a way as to avoid financial losses and improve their financial performance. Finally, understanding the optimal structure of external financing of pharmaceutical companies and evaluating the correctness of this financing may help investors make a decision about investing their own funds in a particular project. However, it also should be mentioned that the results may vary due to the country and industry specifics. Moreover, the size of the sample and the period taken may also change the results of the research as some important factors can be included. For example, the results may be different due to the financial crisis of 2008, the consequences of which may affect the financial performance of the company in subsequent years, but not all studies consider the same period. Secondly, there is a possibility of an insignificant result due to heteroscedasticity and, therefore, inefficiency of estimators [10].

Based on the results of this study, it is able to suggest some recommendations for the further research. Firstly, it is highly commended to use a wider sample of companies, as well as include more financial indicators of the firm performance in order to find more evident relationships between performance indicators and capital structure. Secondly, a greater number of developed countries should be taken into consideration to track the overall trend of the impact of external financing on the company's performance in these countries. It may give further development of the current research and help to explain more relations in the model. Finally, it is suggested to consider the effect of capital structure on company financial performance depending on the size of the company and the level of leverage, which can provide a basis for determining the differences in the impact on samples with different input data. Therefore, the current study can be developed in several areas of further research, which could deepen the scientific understanding of the relationship between key performance indicators of a company and capital structure.

\section{References}

1. Aggarwal, D., \& Padhan, P. C. Impact of Capital Structure on Firm Value: Evidence from Indian Hospitality Industry. Theoretical Economics Letters, 07(04), 982-1000. (2017)

2. Bryman, A., \& Bell, E. Business Research Methods 3e. Oxford, United Kingdom: Oxford University Press. (2011)

3. Hausman, J. Specification Tests in Econometrics. Econometrica, 46, 1251-1271. (1978)

4. Kenton, W. Financial Literacy. Retrieved from https://www.investopportunity.com/terms/f/financial-literacy.asp (2020)

5. Laisi, T. Pecking order theory in a bank-centered lending environment - Evidence from North European economies. University of Vaasa, 1. (2016)

6. Mehdi, M., Farimah, R., Forough, R., Seyed, M., \& Jamshid, S. The Effect of Capital Structure on the Profitability of Pharmaceutical Companies The Case of Iran. Iran J Pharm Res., 573-577. (2013) 
7. Nasimi, A. Effect of Capital Structure on Firm Profitability (An Empirical Evidence from London, UK). Global Journal Of Management And Business Research, 16(4), 820. (2016)

8. Nemlioglu, I., \& Mallick, S. K. Do innovation-intensive firms mitigate their valuation uncertainty during bad times? Journal of Economic Behavior \& Organization, 177, 913-940. (2020)

9. Salim, M., \& Yadav, R. Capital Structure and Firm Performance: Evidence from Malaysian Listed Companies. Procedia - Social and Behavioral Sciences, 65, 156-166. (2012)

10. Tucker, J., \& Stoja, E. Industry membership and capital structure dynamics in the UK. International Review of Financial Analysis, 20(4), 207-214. (2011).

11. Weisberg, S. Applied Linear Regression. Hoboken, NJ, United States: Wiley. (2013)

12. White, H. A Heteroskedasticity-Consistent Covariance Matrix Estimator and a Direct Test for Heteroskedasticity. Econometrica, 48(4), 817. (1980)

13. Wooldridge, J. M. Econometric Analysis of Cross Section and Panel Data. Amsterdam, Netherlands: Amsterdam University Press. (2010)

14. Wooldridge, J. M. Control Function Methods in Applied Econometrics. Journal of Human Resources, 50(2), 420-445. (2015) 